Original Research Article

\title{
Comparison of the treatment mediated changes in serum lipid profile of cases with metabolic syndrome treated with low dose atorvastatin versus the usual care group
}

\author{
Shubhangam Sharma ${ }^{1}$, Hemlata Verma $^{2}$, Anuradha Dubey ${ }^{3}$
}

\begin{abstract}
${ }^{1}$ Department of Pharmacology, MLB Medical College, Jhansi, Uttar Pradesh, India

${ }^{2}$ Department of Pharmacology, Gandhi Medical College, Bhopal, Madhya Pradesh, India ${ }^{3}$ Department of Pharmacology, LN Medical College, Bhopal, Madhya Pradesh, India
\end{abstract}

Received: 16 January 2017 Accepted: 13 February 2017

*Correspondence to:

Dr. Shubhangam Sharma, Email: drshubh07@gmail.com

Copyright: (C) the author(s), publisher and licensee Medip Academy. This is an openaccess article distributed under the terms of the Creative Commons Attribution NonCommercial License, which permits unrestricted noncommercial use, distribution, and reproduction in any medium, provided the original work is properly cited.

\begin{abstract}
Background: Metabolic syndrome (MetS) is a constellation of cardiometabolic risk determinants comprising of obesity, insulin resistance, dyslipidaemia and hypertension. In view of the epidemic of metabolic syndrome, this prospective, comparative study done in OPD setting in a tertiary care centre of central India aimed at finding out the changes in lipid profile, a surrogate marker of cardiovascular morbidities on treatment with low dose atorvastatin versus the usual care group.

Methods: Patients satisfying NCEP-ATPIII criteria for metabolic syndrome were divided into two groups. Group A received treatment with $20 \mathrm{mg}$ Atorvastatin along with target driven treatment for hypertension and elevated glucose, as required. Group B received the same except for atorvastatin. Serum lipid profiles were recorded and changes were compared before and after study duration of 3 months. Also, cardiac events were kept track of during follow up.

Results: At the end of study it was found that treatment mediated changes in the lipid profile were highly significant $(\mathrm{p}<0.001)$ and favourable in group A as compared to Group B. Also, lesser cardiovascular outcomes were observed in Group A patients.

Conclusions: The study concludes that among patients with metabolic syndrome, those treated with statins benefitted more than those who did not take statin therapy. This benefit in the correction of serum lipid profile also translated in terms of decreased cardiovascular outcomes in Group A patients. Hence, low dose atorvastatin therapy provides a potential approach for treatment of patients with metabolic syndrome.
\end{abstract}

Keywords: Atorvastatin, HDL- cholesterol, Lipid profile, LDL- cholesterol, Metabolic syndrome, Triglycerides

\section{INTRODUCTION}

Metabolic syndrome (MetS) is a constellation of cardiometabolic risk determinants comprising of obesity (Central adiposity), glucose intolerance and insulin resistance, dyslipidaemia (including hypertriglyceridemia, increased free fatty acids and decreased HDL- Cholesterol) and hypertension. ${ }^{1,2}$ It has also been recently associated with clinical manifestations such as PCOS (Polycystic Ovarian Syndrome) atherosclerosis, proinflammatory state, oxidative stress and NAFLD (non-alcoholic fatty liver disease). ${ }^{3-5}$ There is a strong correlation between the increase in MetS prevalence and increasing obesity prevalence. Visceral obesity is the mechanistic link between the components of MetS. The increasing BMI also correlates with other MetS components, including increasing total cholesterol, LDL- cholesterol and triacylglycerols and decreasing HDL- cholesterol and hypertension. ${ }^{6}$

Statins are one of the major pharmacotherapeutic modalities for lipid management which also reduce coronary events in population at risk and in patients with stable coronary disease. ${ }^{6,7}$ These are the most effective 
and best tolerated agents for the treatment of dyslipidemia. These drugs are competitive and reversible inhibitors of HMG-CoA reductase which plays a central role in the production of cholesterol in the liver. Because statins are similar to HMG-CoA on a molecular level they take the place of HMG-CoA in the enzyme and reduce the rate by which it is able to produce mevalonate, the next molecule in the cascade that eventually produces cholesterol, as well as a number of other compounds. Their predominant action is to reduce circulating levels of low-density lipoprotein (LDL) cholesterol, they also increase high-density lipoprotein (HDL) cholesterol and reduce triglyceride and VLDL concentrations. ${ }^{7}$ Statins also have some direct cardio protective role which is independent of the lipid lowering action like antioxidant effect of statins, effect on coagulation, inflammation, plaque stability and endothelium collectively known as the pleiotropic effects of statins. ${ }^{7}$

Metabolic syndrome is rapidly increasing in prevalence worldwide as a consequence of continued obesity 'epidemic' and thus will have a considerable impact on the global incidence of cardiovascular disease and type 2 diabetes. ${ }^{8-11}$ Ectopic fat accumulation such as visceral and hepatic fat and the pro-inflammatory state are central to the development of the MetS. ${ }^{12}$ This work was, therefore, undertaken to establish the response of statin therapy in metabolic syndrome patient population of central India and to measure the treatment mediated variations in lipid profiles of patients receiving statin therapy vs. those who were not.

\section{METHODS}

This prospective and randomized observational study was conducted in the OPD patients at a tertiary care hospital in Bhopal. This study has been conducted observing ethical guidelines of Biomedical research on human participants following ethical review procedures, general ethical issues enshrined therein for prospective studies and after approval from the institutional ethical committee, as required.

\section{Inclusion criteria}

- Patients ready to give consent for the study.

- $\quad$ Age group 20-70 years.

- $\quad$ Patients satisfying at least 3 parameters of metabolic syndrome as per NCEP ATP-III (National Cholesterol Education Program Adult Treatment Panel III) criteria.

\section{Exclusion criteria}

- Patients not ready to give consent for study.

- $\quad$ Age less than 20 years and greater than 70 years.

- Patients with recent Myocardial infarction.

- Pregnancy.

- Patients already taking statins or other hypolipidaemic drugs.

\section{Grouping of patients}

Patient were divided into 2 groups

1. Group A: Patients satisfying at least 3 parameters of metabolic syndrome as per the NCEP ATP-III criteria, who received statin therapy (Atorvastatin $20 \mathrm{mg} /$ day).

2. Group B: Patients satisfying at least 3 parameters of metabolic syndrome as per the NCEP-ATP-III criteria, but did not take statin therapy due to any of the following reasons.

- Non-compliance.

- Contra-indications.

A total of 90 cases were studied in which group A (patients receiving statin therapy) included 68 cases $(\mathrm{n}=68)$ and group B (patients not taking statin therapy) included 22 cases $(n=22)$. The cases were followed up for 3 months.

\section{Evaluation}

The outcomes studied were:

- Primary outcome: Changes in serum lipid profile after 3 months of treatment.

- Secondary outcome: Clinical outcomes in terms of cardiac events.

\section{Investigations}

Estimation of the serum lipid profile at the baseline and at the end of study was done along with routine investigations.

\section{Statistical analysis}

Results were recorded in a tabulated manner and presented as mean and standard deviation for quantitative variables. For assessing changes in study parameters after drug intervention compared with before that, the paired $t$ test was used. A p-value of less than 0.001 was considered statistically significant.

\section{RESULTS}

The outcome parameter for the present study was to evaluate the changes in the lipid profile of the patients subjected to statin therapy and to compare it with those who did not take statin therapy. In the study, it was found that lipid levels improved significantly in group A which received $20 \mathrm{mg} /$ day Atorvastatin for 3 months. In group A the level of LDL-cholesterol decreased by $26.66 \%$ $(p<0.001)$ after a duration of 3 months, total cholesterol level dropped down by $18.03 \% \quad(\mathrm{p}<0.001)$, serum triglyceride and VLDL levels recorded $18.33 \%$ and $7.6 \%$ $(\mathrm{p}<0.001)$ fall in the levels, respectively and HDLcholesterol levels increased by $9.35 \%(\mathrm{p}<0.001)$. 
In group B (patients having metabolic syndrome according to the NCEP-ATP-III criteria who did not take statins), these changes were not significant.

In this group, the total cholesterol level decreased only by $10.69 \%$ after duration of 3 months, LDL-cholesterol dropped down by $13.17 \%$, serum triglyceride and VLDL had $5.6 \%$ and $3 \%$ decrease in the levels, respectively and HDL-cholesterol increased by $3.3 \%$. It was observed that only $1.4 \%$ patients developed cardiac events in group A whereas $4 \%$ patients developed cardiac events in group B. The cardiovascular disease risk reduction offered by statins is attributable to its pleiotropic effects also apart from the lipid profile correction property.

Table 1: Age group wise distribution of cases.

\begin{tabular}{|lllllllll|}
\hline \multirow{2}{*}{ S. No. } & Age group (yrs) & \multicolumn{2}{c}{ Group A $(\mathbf{n = 6 8 )}$} & \multicolumn{2}{l|}{ Group B (n=22) } & \multicolumn{2}{l|}{ Total } \\
\hline 1 & $21-30$ & No. & $\mathbf{\%}$ & No. & $\mathbf{\%}$ & No. & \% \\
\hline 2 & $31-40$ & 6 & 8.8 & 1 & 4.5 & 7 & 7.7 \\
\hline 3 & $41-50$ & 8 & 11.76 & 4 & 18.18 & 12 & 13.33 \\
\hline 4 & $51-60$ & 27 & 39.7 & 9 & 40.9 & 36 & 40 \\
\hline 5 & $61-70$ & 20 & 29.41 & 6 & 27.27 & 26 & 28.8 \\
\hline & Total & 7 & 10.29 & 2 & 9 & 9 & 10 \\
\hline
\end{tabular}

\section{Demographic details}

Table 2: Sex wise distribution of cases.

\begin{tabular}{|lllllll|}
\hline Sex & \multicolumn{2}{l}{$\begin{array}{l}\text { Group A } \\
(\mathbf{n = 6 8})\end{array}$} & \multicolumn{2}{l}{$\begin{array}{l}\text { Group B } \\
(\mathbf{n = 2 2})\end{array}$} & \multicolumn{2}{l|}{ Total } \\
& No. & \% & No. & \% & No. & \% \\
\hline Males & 30 & 44.11 & 10 & 45.5 & 40 & 44.5 \\
\hline Females & 38 & 55.88 & 12 & 54.5 & 50 & 55.5 \\
\hline Total & 68 & 100 & 22 & 100 & 90 & 100 \\
\hline
\end{tabular}

Table 3: Centripetal obesity in the study population.

\begin{tabular}{|lllllll|}
\hline Obesity & \multicolumn{2}{l}{$\begin{array}{l}\text { Group A } \\
(\mathbf{n = 6 8})\end{array}$} & \multicolumn{2}{l}{$\begin{array}{l}\text { Group B } \\
(\mathbf{n = 2 2})\end{array}$} & \multicolumn{2}{l|}{ Total } \\
& No. & \% & No. & \% & No. & \% \\
\hline Obese & 51 & 75 & 16 & 72.7 & 67 & 74.4 \\
\hline Non-obese & 17 & 25 & 6 & 27.27 & 23 & 25.5 \\
\hline Total & 68 & 100 & 22 & 100 & 90 & 100 \\
\hline
\end{tabular}

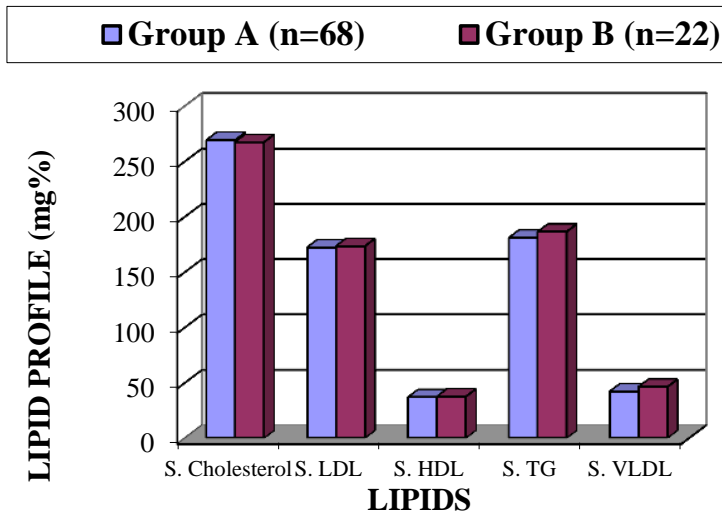

Figure 1: Serum lipid profile in both the groups at baseline.
Table 4: High B.P. in the study population according to the NCEP-ATP-III criteria.

\begin{tabular}{|lllll|ll|}
\hline & \multicolumn{2}{l}{$\begin{array}{l}\text { Group A } \\
\text { B.P. }\end{array}$} & \multicolumn{2}{l|}{$\begin{array}{l}\text { Group B } \\
(\mathbf{n = 6 8})\end{array}$} & \multicolumn{2}{c|}{ Total } \\
& No. & $\%$ & No. & $\%$ & No. & $\%$ \\
\hline $\begin{array}{l}\text { Having } \\
\text { high B.P. }\end{array}$ & 56 & 82.4 & 18 & 81.8 & 74 & 82.3 \\
\hline $\begin{array}{l}\text { Not having } \\
\text { high B.P. }\end{array}$ & 12 & 17.6 & 4 & 18.2 & 16 & 17.7 \\
\hline Total & 68 & 100 & 22 & 100 & 90 & 100 \\
\hline
\end{tabular}

B.P.- Blood pressure

Table 5: High Fasting Plasma glucose in the study population according to the NCEP-ATP-III criteria.

\begin{tabular}{|lllllll|}
\hline & \multicolumn{2}{l}{$\begin{array}{l}\text { Group A } \\
(\mathbf{n = 6 8})\end{array}$} & \multicolumn{2}{l|}{$\begin{array}{l}\text { Group B } \\
(\mathbf{n = 2 2})\end{array}$} & \multicolumn{2}{l|}{ Total } \\
& No. & \% & No. & \% & No. & \% \\
\hline FPG-High & 52 & 76.4 & 16 & 72.7 & 68 & 75.5 \\
\hline FPG-not high & 16 & 23.5 & 6 & 27.2 & 22 & 24.4 \\
\hline Total & 68 & 100 & 22 & 100 & 90 & 100 \\
\hline
\end{tabular}

FPG-Fasting Plasma Glucose

\section{DISCUSSION}

The outcome parameters for the study were the changes in the lipid profile of the patients. The characteristics of the patients in both the groups (Group A - Patients having metabolic syndrome as per the NCEP-ATP-III criteria who received statin therapy and Group B - Patients having metabolic syndrome as per NCEP-ATP-III criteria who did not receive statin therapy) in terms of age group, sex wise distribution, lipid profile were comparable at baseline. In the study, it was found that lipid profile improved significantly in group A which received 20 
mg/day Atorvastatin for 3 months. In group B, these changes were not significant.

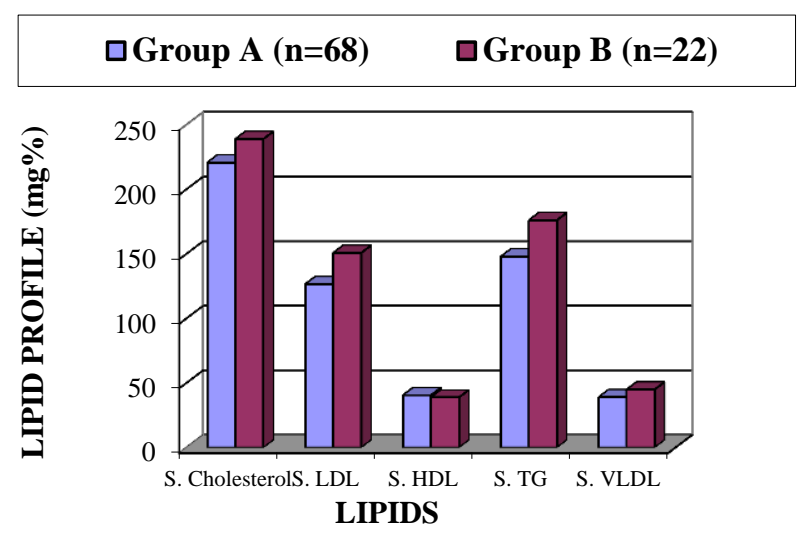

Figure 2: Serum lipid profile in both the groups at end of the study.

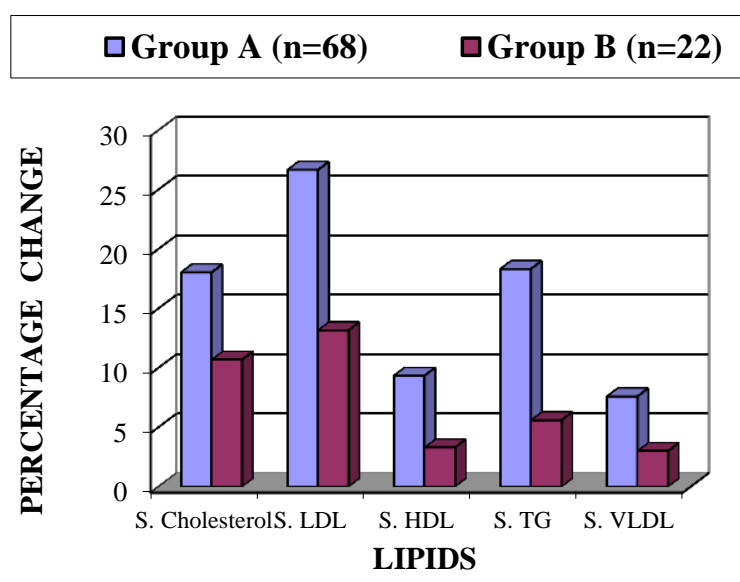

Figure 3: Percentage changes in different variables of lipid profile in group $A$ and $B$ after the treatment.

In group $\mathrm{A}$; the level of LDL-cholesterol decreased by $26.66 \%$, total cholesterol level dropped down by $18.03 \%$, serum triglyceride level recorded $18.33 \%$ fall and HDLcholesterol levels increased by $9.35 \%$. The results of the present study are in agreement with the landmark trial, the Scandinavian Simvastatin survival study (4S trial) involving 4444 patients with moderate hypercholesterolemia, in which the reduction recorded in total cholesterol levels was $29 \%$, LDL cholesterol and TG dropped by $35 \%$ and $10 \%$, respectively whereas HDL cholesterol increased by $8 \%$.

The Cholesterol and Recurrent Events (CARE) trial, the Long-term Intervention with Pravastatin in Ischaemic Disease (LIPID) trial and The Greek Atorvastatin and Coronary Heart disease Evaluation2002 (GREACE study)showed $20 \%, 18 \%$ and $36 \%$ reductions, respectively in total cholesterol levels on treatment with statins. ${ }^{13-17}$ Similar observations were reported in the Atorvastatin Comparative Cholesterol Efficacy and Safety Study (ACCESS) and Heart Protection Study
(HPS) in which drop in the levels of LDL-C were $36 \%$ and $29 \%$ respectively. ${ }^{18,19}$ In the present study there was a decline in LDL-C level in group B also, who had not taken statins. This can be explained as by diet control and other medications for co-morbidities.

In the present study, the level of HDL-cholesterol was observed to rise by $9.35 \%$ in group A. Similar changes were observed in various studies like Investigation of Rosuvastatin in South Asians (IRIS study) in which the HDL levels rose by $19 \%$ in patients with metabolic syndrome treated with statins. ${ }^{21}$

The ACCESS study suggested that Atorvastatin increased the HDL-C levels by $4-6 \%$ in various groups. ${ }^{18}$ The statin secondary prevention trials also have proved to produce a significant rise in the HDL-C levels.4S,CARE, LIPID and the GREACE trials have shown a rise of $8 \%, 5 \%, 6 \%$ and $7 \%$ in the HDL-C levels, respectively. ${ }^{13,14,15,17}$

In the present study, the levels of triglycerides and VLDL were observed to decline by $18.33 \%$ and $7.6 \%$ respectively in Group A. The ACCESS study suggested that Atorvastatin produced greatest mean reduction in triglyceride levels at 6 weeks by $18 \%$ and $19 \%$ at 54 weeks. ${ }^{18}$ These results are also consistent with $4 \mathrm{~S}$ which reported $10 \%$ fall in the level of triglycerides and CARE, LIPID and GREACE studies which reported 14\%, 12\% and $31 \%$ fall, respectively. ${ }^{13-17}$

A comparison of secondary outcomes revealed that group A patients developed lesser cardiac events (1.4\%) than group B (4\%). Similar findings have been reported in various clinical trials involving statins as therapeutic agents in MetS. Landmark trials like 4S, CARE, LIPID and GREACE have shown statins to reduce the CHD events by $33 \%, 24 \%, 23 \%$ and $51 \%$ respectively; all these changes were statistically significant compared to those achieved in usual care group. ${ }^{13-15,17}$

The metabolic syndrome is a common metabolic disorder that results from the increasing prevalence of obesity. The disorder is defined in various ways, but in the near future a new definition will be applicable worldwide establishing the mechanistic link between excessive flux of fatty acids and pathophysiology of metabolic syndrome. Hence, although the fundamental approach is weight reduction and increased physical activity; the study concludes that drug treatment with low dose atorvastatin is pivotal in affording lipid profile correction and cardiovascular disease risk reduction.

\section{ACKNOWLEDGEMENTS}

Authors would like to express their gratitude towards faculty members of department of Cardiology and also to all the patients enrolled in this study for their support and co-operation which enabled the conduction and completion of this study. Authors would like to express their deep gratitude towards Dr. Sarabjeet Singh Sir (DM 
Clinical Pharmacology) for his unstinting support and encouragement.

Funding: No funding sources

Conflict of interest: None declared

Ethical approval: The study was approved by the Institutional Ethics Committee

\section{REFERENCES}

1. Metabolic syndrome (also called insulin resistance syndrome). (National Institutes of Health); Clinical Trials.gov: Medline Plus: Available at: https://medlineplus.gov/metabolicsyndrome.html

2. Grundy SM. Metabolic Syndrome: A multiplex cardiovascular risk factor, Journal of Clinical Endocrinology and Metabolism. 2007;92(2):399-404.

3. Eapen D, Kabra GL, Merchant N, Arora A, Khan BV. Metabolic syndrome \& cardiovascular disease in South Asian. Vascular Health and Risk Management. 2009;5:731-43.

4. Misra A, Khurana L. The metabolic syndrome in South Asians: epidemiology, determinants, and prevention, Metabolic syndrome and related disorders. 2009(7);497-514.

5. Libby P. Prevention and treatment of Atherosclerosis in Kasper Braunwald Fauci eds. Harrison's principles of internal medicine.16th edition. McGraw-Hill Medical; 2005:1430-1433.

6. McNamara JR, Campos H, Ordovas JM, Peterson J, Wilson PW, Schaefer EJ. Effect of gender, age, and lipid status on low density lipoprotein sub fraction distribution. Results of the Framingham Offspring Study. Arteriosclerosis. 1987;7(5);483-90.

7. Thomas P. Bersot Drug therapy for Hypercholestremia and Dyslipidemia. In: Laurence Brunton Bruce Chabner Bjorn Knollman eds. Goodman and Gilmans' - The Pharmacological Basis of Therapeutics $12^{\text {th }}$ Edition, McGraw Hill; 2011:893-894.

8. Fukuchi S, Hamaguchi K, Seike M, Himeno K, Sakata T, Yoshimatsu H. Role of Fatty Acid Composition in the Development of Metabolic Disorders in Sucrose-Induced Obese Rats. Exp Biol Med. 2004;229(6):486-93.

9. Diabetes and Metabolism. Metabolic syndrome is becoming increasingly common. It occurs when a range of metabolic risk factors such as obesity and insulin resistance come together. Available at: http://www.diabetes.co.uk/diabetes-and-metabolicsyndrome.html

10. Larsson B, Svardsudd K, Welin L, Wilhelmsen L, Bjorntorp P, Tibblin G. Abdominal adipose tissue distribution, obesity, and risk of cardiovascular disease and death: 13 year follow up of participants in the study of men born in. $\mathrm{Br}$ Med $\mathrm{J}$. 1984;288:1401-04.

11. Despres JP, Moorjani S, Lupien PJ, Tremblay A, Nadeau A, Bouchard C. Regional distribution of body fat, plasma lipoproteins, and cardiovascular disease. Arteriosclerosis. 1990;10(4):497-511.

12. Bruce KD, Byrne CD. The metabolic syndrome: common origins of a multifactorial disorder. Postgrad Med J. 2009;85(1009):614-21.

13. Pedersen TR, Kjekshus J, Berg K, Haghfelt T, Faergeman O, Faergeman $\mathrm{G}$ et al. Randomized trial of cholesterol lowering in 4444 patients with coronary heart disease; the Scandinavian Survival Study. Atherosclerosis. 2004;5(3):81-7.

14. The Long-Term Intervention with Pravastatin in Ischemic Heart Disease (LIPID) Study Group. Prevention of cardiovascular events and death with pravastatin in patients with coronary heart disease and a broad range of initial cholesterol levels. N Eng. J. Med. 1998;339:1349-57.

15. Lewis SJ, Moye LA, Sacks FM, Johnstone DE, Braunwald E. Effect of Pravastatin on Cardiovascular Events in Older Patients with Myocardial Infarction and Cholesterol Levels in the Average Range: Results of the Cholesterol and Recurrent Events (CARE) Trial N Engl J Med. 1996;335:1001-9.

16. Athyros VG, Papageorgiou AA, Mercouris BK. Treatment with atorvastatin to the National Cholesterol Education Program versus 'usual' care in secondary -Coronary heart disease prevention. Current Medical Research and Opinion. 2002;18(4):220-28.

17. Mikhailidis DP, Wierzbicki AS. The Greek Atorvastatin and Coronary-heart-disease Evaluation (Greace) study. Curr. Med. Res Opin. 2002;18(4):215-9.

18. Atorvastatin comparative cholesterol efficacy and safety study. Department of Health Management and Policy, University of Michigan, Ann Arbor, USA. 2003; 21(1):13-23.

19. Collins R, Armitage J, Parish S, Sleight P, Peto R. Heart Protection Study Collaborative Group. Effects of cholesterol-lowering with simvastatin on stroke and other major vascular events in 20536 people with cerebrovascular disease or high- risk conditions. Lancet. 2004;363(9411):757-67.

20. Heart Protection Study Collaborative Group, MRC/BHF Heart Protection Study of cholesterol lowering with simvastatin in 20536 high-risk individuals; a randomized placebo-controlled trial. 2002;360(9326):7-22.

21. Deedwania PC, Gupta M, Stein M, Ycas J, Gold A. IRIS Study Group. Comparison of rosuvastatin versus atorvastatin in South-Asian patients at risk of coronary heart disease (from the IRIS Trial) Am J Cardiol. 2007;99:1538-43.

Cite this article as: Sharma S, Verma H, Dubey A. Comparison of the treatment mediated changes in serum lipid profile of cases with metabolic syndrome treated with low dose atorvastatin versus the usual care group. Int J Basic Clin Pharmacol 2017;6:624-8. 